\title{
Coleta de esperma infértil em laboratório: prática médica ou sexual?
}

\section{| ${ }^{1}$ Alain Giami, ${ }^{2}$ Doris Vasconcellos-Bernstein |}

Resumo: Os protocolos de assistência médica à procriação comportam um exame biológico do esperma, realizado graças à masturbação praticada em locais inadequados para uma prática geralmente considerada erótica. Realizou-se investigação etnográfica em dois grandes hospitais parisienses. Os homens e as mulheres que participaram manifestaram reações subjetivas, associando constrangimento, vergonha, desagrado e nojo diante da prática da masturbação nesse contexto. A confusão entre os registros médico e sexual, as dificuldades para des-sexualizar uma prática que permanece como tabu e a natureza estéril do esperma produzido nessas circunstâncias seriam a causa das reações emocionais experimentadas em relação ao esperma, quando este é produzido no contexto médico.

Palavras-chave: esperma; infertilidade; masturbação; assistência médica à procriação.

\author{
1 Diretor de Pesquisas, InNSERM, \\ CESP Center for Research in \\ Epidemiology and Population \\ Health, U1018, Team 07: Gender, \\ Sexual and Reproductive Health, \\ F-94276, Le Kremlin Bicêtre, \\ France. Endereço eletrônico: \\ alain.giami@inserm.fr \\ 2 Professora de Psicopatologia, \\ Universidade Paris Descartes, \\ Paris, França. Endereço \\ eletrônico: doris.vasconcellos@ \\ free.fr
}

Recebido em: 19/02/2013 Aprovado em: 30/12/2013 


\section{A coleta de esperma: entre biologia e antropologia}

Os procedimentos biomédicos que permitem a assistência médica à procriação $(\mathrm{AMP})$ só são possíveis graças à masturbação masculina, praticada em laboratório de análises biológicas. Trata-se de uma das raras prescrições médicas que não requerem técnica médica sofisticada, e que possui relevante peso simbólico pelo fato de ser obtida por meio de uma prática sexual, a fortiori de uma prática sexual não reprodutiva e estigmatizada ao longo da história da civilização ocidental (FOUCAULT, 1976; LAQUEUR, 2003; SZASZ, 1976).

No contexto da AMP, basicamente duas situações de masturbação podem ocorrer: por um lado, a efetuada por generosos doadores de esperma (KIRKMAN, 2004), para fecundar mulheres férteis cujo cônjuge é estéril, ou mulheres que não desejam procriar por via sexual. Esta é a situação que visa prover os bancos de esperma em certos países (TOBER, 2001); por outro lado, a situação dos homens que suspeitam ou "sabem", antes de entrar nos espaços reservados para esta prática, que o esperma que vão produzir de maneira laboriosa é infértil. Estas situações provocam reações radicalmente distintas: o orgulho relacionado à fertilidade dos primeiros contrasta com a vergonha e a tensão expressas pelos outros.

Trata-se, portanto, de um fluido corporal e de uma prática fortemente carregados de significados simbólicos, que não são redutíveis aos significados atribuídos a estes elementos sob a ótica restrita da biomedicina. Nosso enfoque se inscreve na perspectiva de uma antropologia da doença (AUGÉ, 1986; LAPLANTINE, 1986) e da psicologia crítica da saúde (MURRAY, 2004).

Nesse sentido, a título de exemplo, podemos observar que de acordo com a acepção da biomedicina, os termos "coleta de esperma" e "espermograma" se distinguem da experiência de alguns homens entrevistados, em referência às experiências de confrontação com a infertilidade. O que a medicina designa como "coleta de esperma" e "espermograma”, para um homem investigado, seria "uma punheta reembolsada pela Sécu" ${ }^{1 "}\left(\mathrm{Daniel}^{2}\right)$, para certas mulheres, como "uma carga" (Cécile) ou, até, como "um horror" (Mireille). No entanto, quando Pierre afirma que ele não é "verdadeiramente um homem”, verifica-se um registro com um significado subjetivo, decorrente da situação de coleta de esperma, que alude à ameaça à virilidade, provocada pela descoberta da infertilidade (COEFFINDRIOL; GIAMI, 2004). O objeto deste artigo é a análise detalhada da confusão entre os significados subjetivos "próximo da experiência” (eróticos), e médicos 
"distante da experiência" (GEERTZ, 1983) da masturbação como principal

meio de produção e coleta de esperma.

\section{Coleta dos dados em dois centros parisienses}

Esta pesquisa foi realizada em $2004,{ }^{3}$ em dois hospitais universitários da região parisiense. Observamos as consultas de três médicos (laboratório de exames biológicos, consulta de urologia-andrologia e centro de assistência médica à procriação), que trabalhavam conectados. Passamos muito tempo nesses serviços assistindo às consultas, observando os locais e o ambiente, em conversas informais com as equipes médicas e com técnicos de laboratório. Nesta imersão também tivemos a oportunidade de ter acesso à documentação técnica e regulamentar. No total, observamos 168 consultas, de três médicos, utilizando uma tabela de observação sistemática. ${ }^{4}$ No término de cada consulta, se o casal correspondia aos critérios de inclusão (não ter filhos, não ter experiência anterior de fecundação in vitro), era proposto ao homem ou à mulher (de maneira aleatória, segundo o dia da semana) participar da pesquisa através de uma entrevista semidirigida. Explicávamos que a entrevista seria efetuada por um pesquisador(a) que não assistiu àquela consulta e que não haveria qualquer consequência concernente à continuação do tratamento. Um formulário de "consentimento livre, esclarecido e

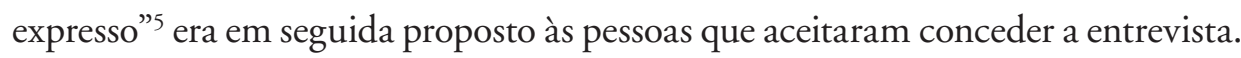

O protocolo previa o recrutamento de pessoas que ainda não haviam sido beneficiadas com tratamento de infertilidade e não possuíam filhos. Quinze homens e nove mulheres foram recrutados para a pesquisa. As entrevistas foram gravadas e integralmente transcritas para análise. O recrutamento foi empreendido sem insistência, com o objetivo de não provocar qualquer interferência no processo do tratamento, o que justifica o escasso número de voluntários.

Cabe acrescentar que, no momento da entrevista, a maioria dos homens já havia recebido o diagnóstico de infertilidade, ou de hipofertilidade, a partir dos resultados dos exames realizados sobre a qualidade do esperma. Com efeito, antes de qualquer tentativa de fecundação ou inseminação, alguns destes homens já tinham sido submetidos a vários espermogramas, em diferentes momentos do diagnóstico. Esse dado é importante, pois permite compreender que nossas entrevistas não se inscrevem na cronologia do percurso médico relatado por esses homens, mas decorrem de uma reconstrução narrativa da experiência 
marcada pelo conhecimento do resultado negativo obtido nos espermogramas. Vale observar que estes homens e mulheres desejavam falar desta experiência apesar de, ou talvez devido ao sofrimento vivido, e que a entrevista realizada por psicólogos clínicos respondia, assim, a uma demanda por parte dessas pessoas.

As primeiras transcrições foram estudadas pelos membros da equipe e uma tabela de análise de conteúdos temáticos foi elaborada, com os principais temas da investigação, para sistematização dos dados individuais (GIAMI et al., 1995). A análise dos procedimentos biomédicos em relação à coleta de esperma e os significados atribuídos a esta prática concernem à coleta, ao estudo dos documentos que a regulamentam e à observação das consultas. Este material foi examinado, e os dados relacionados aos depoimentos concedidos pelos homens entrevistados. Encontramo-nos diante de um contexto com um dispositivo complexo, cuja análise está baseada no exame de diferentes fontes de informação: as entrevistas com homens e mulheres implicados no processo; a observação das consultas e das práticas dos laboratórios; as conversas informais com médicos, enfermeiras e técnicos, além da leitura do regulamento e os guias de boas práticas.

\section{O esperma: um objeto simbólico}

Os sentidos da coleta de esperma não podem ser reduzidos às realidades e concepçôes biomédicas, que interessam prioritariamente aos médicos. $\mathrm{O}$ esperma representa uma substância biológica associada a valores simbólicos que tornam sua manipulação relativamente complexa. A produção de esperma infértil necessária para a realização de um exame biológico - o espermograma - é fundamentalmente diferente do valor do esperma fértil. Quando um homem sabe da boa qualidade de seu esperma e se propõe a oferecê-lo às mulheres e aos casais que não dispõem desse patrimônio biológico, ele se inscreve num cenário imaginário no qual ele se sente capaz de fertilizar toda a humanidade. Trata-se do modelo da veterinária dos touros e dos garanhões, cuja fertilidade está conectada à potência sexual e ao poder do macho sobre a fêmea. Nessa situação altamente euforizante, a masturbação dirigida à produção desse líquido fecundo não constitui um problema para os homens. A situação é erotizada, eufórica, marcada pelo prazer e pela vida (KIRKMAN, 2004), e se insere na maioria dos significados atribuídos ao esperma.

Em certas culturas, o esperma é considerado nutriente para o desenvolvimento do feto (Samo, de Burkina Fasso) (HÉRITIER, 1984; HÉRITIER-AUGÉ, 
1985), como um elemento simbólico que contribui para a transmissão da identidade cultural, ou da identidade de gênero, na cultura Baruya (NovaGuiné): o esperma dos homens adultos pode ser absorvido por via oral pelos meninos, para que "se tornem homens" e, assim, alcancem a condição adulta (GODELIER, 2005; Herdt, 1981).

No mundo ocidental, também são encontrados significados eufóricos associados à produção de esperma na pornografia. A ejaculação masculina no exterior dos orifícios de penetração e, por vezes, até a "ejaculação facial" (dirigida voluntariamente para o rosto da parceira) constitui a "apoteose do espetáculo". Mais ainda, trata-se de um dos poucos elementos de realidade que não pode ser simulado em espetáculos pornográficos (HIRT, 1984). Portanto, esse tipo de performance é passível de produzir excitação sexual, pois este é o objetivo da pornografia. Contudo, também sabemos que a pornografia suscita reações opostas, como o nojo, constatado por certas observadoras (STOLLER, 1991).

Seria essa aversão origem ou consequência das interdições de manipulação do esperma ditadas por determinadas culturas? Cabe referir que essa situação ocorre principalmente quando o esperma não é fértil, ou não destinado a fertilizar, como ocorre na pornografia. O contato com líquidos corporais, como o esperma e a menstruação, constitui fonte de impureza e tabu (WEBSTER, 1942). Às vezes recomenda-se aos homens e às mulheres que acabaram de ter relações sexuais, ou que têm relações sexuais frequentes, que não se aproximem de coisas sagradas ou que não se aproximem de doentes ou de feridos, a partir da suposição de que o esperma foi expelido sobre a pele. Nas culturas tradicionais ocidentais e, particularmente, na cultura judia tradicional, a produção de esperma fora da vagina e em período de fecundidade da mulher é considerada como pecado, e o produto resultante, uma impureza (DOUGLAS, 1966; BIALE, 1997). Em algumas culturas árabes (Líbano, Síria) Inhorn (2007) evidenciou como a culpa associada à proibição da masturbação reaparece quando os homens inférteis são confrontados com as práticas biomédicas do espermograma.

A emergência da epidemia da Aids renovou o conjunto de significados simbólicos do esperma, acrescentando a dimensão da morte, da doença e da transgressão da ordem sexual, dimensóes pouco presentes nos significados tradicionais do esperma (GIAMI; VEIL, 1994; SONTAG, 1988).

O mundo médico-científico está longe de ser impermeável aos significados culturais. Por exemplo, nos Estados Unidos, as normas religiosas constituíram 
1322 relevante obstáculo ao desenvolvimento da pesquisa sobre o esperma. Entre 1930 e 1945, a masturbação não era considerada um método aceitável para coleta de amostras de esperma, e foi preciso que os pesquisadores inventassem outros meios, por exemplo, com preservativos de látex utilizados em situação de coito (MOORE, 2002; CLARKE, 1998). Na França encontramos apenas um estudo sistemático das condiçôes materiais e psicológicas da coleta de esperma, que remonta a 1977 (JOUANNET; DAVID, 1977). Esta quase ausência de trabalhos científicos leva a pensar que os clínicos e pesquisadores que trabalham com o esperma parecem ter pouco interesse pelo "fator humano" mobilizado nessa prática. Talvez tenham se inspirado na tradição veterinária, quando a coleta de esperma, com o objetivo de inseminação artificial, não provoca o mesmo tipo de problema? Por fim, é surpreendente a restrita busca por outros dispositivos que permitam a coleta de esperma, a partir da sua emissão genital, além da masturbação manual, independentemente dos métodos cirúrgicos (GERRIS, 1999).

\section{Coleta de esperma: uma prática médica banalizada?}

A coleta de esperma ${ }^{6}$ constitui uma das passagens obrigatórias para os homens inseridos numa relação conjugal e que iniciam um percurso de AMP. Consiste numa masturbação prescrita por um médico, visando realizar um espermograma e/ou uma cultura de esperma, exames de laboratório para elaboração de um diagnóstico, cujo resultado a priori é ignorado.

Esse diagnóstico exerce importante influência sobre o desenrolar do protocolo de AMP proposto para o casal. A coleta de esperma ocorre, em geral, em local destinado para este fim, em laboratório de análises biológicas ou, mais raramente, no domicílio dos interessados. A coleta também pode ser efetuada no dia da punção dos ovócitos, no decorrer do tratamento para uma FIV, antes do encontro dos gametas no laboratório, visando a uma criopreservação ou doação de esperma. Estas três situações, concernentes ao conhecimento do caráter fértil do esperma, não serão aqui consideradas. Este estudo é dirigido apenas à coleta de esperma em contexto de AMP, quando há investigação de diagnóstico de infertilidade ou de hipofertilidade. Esta situação, raramente abordada pela literatura científica, é muito mais problemática para os homens e para as mulheres que a vivenciam, do que quando a coleta de esperma conduz à constatação da fertilidade masculina (KIRKMAN, 2004). 


\section{Observações etnográficas}

Em um dos serviços observados, o médico responsável se opunha a disponibilizar revistas eróticas sob sua responsabilidade pessoal, por considerar inadequada a imposição de um modelo sistemático de estimulação sexual. Assim, os homens tinham liberdade para fazer o que desejassem para produzir o esperma. Por vezes, o regulamento interno do laboratório se encontra em exposição, de maneira visível nos locais destinados à coleta do esperma: trata-se principalmente de respeito às condições de higiene e de segurança. A partir dessa lógica, a presença da parceira e sua eventual participação na coleta do esperma é atribuída tanto à conveniência ou arbitrariedade do laboratório quanto à escolha dos clientes. ${ }^{7}$

$\mathrm{O}$ depoimento de um homem que efetuou coleta de esperma exploratória em um laboratório privado é ilustrativo. O serviço está situado em um bairro de nível socioeconômico elevado de Paris e conta com uma decoração diferente dos serviços públicos. O paciente é acolhido por uma recepcionista em um local luxuoso e, após esclarecimentos sobre o seguro de saúde, é conduzido ao local para a coleta de esperma. Neste confortável espaço há um projetor de DVD sofisticado, com tela plana e controle remoto, com um acervo de filmes pornográficos que oferecem toda uma variedade de fantasias sexuais apropriadas para facilitar a ejaculação. A recepcionista diz que ele fique à vontade e que disponha do tempo que quiser. Quando o produto da coleta tiver sido depositado no recipiente adequado, o paciente pode se preparar para partir, comunicandose com a recepcionista por um controle remoto. Este dispositivo evita o contato visual com as recepcionistas, após a realização da coleta do esperma. Assim evitase um potencial constrangimento causado pela masturbação. Esta maneira de lidar com a situação contrasta com o que observamos na maioria dos laboratórios, tanto do ponto de vista do conforto e do ambiente agradável do local quanto no que concerne ao encontro com os profissionais de saúde após a coleta.

Em um dos estabelecimentos observados, não há qualquer regra, além das recomendações técnicas, visíveis na parece da sala onde se desenrola a "coleta do esperma”. Nesse laboratório ninguém, nem mesmo as enfermeiras, tem conhecimento acerca da existência de um protocolo escrito, sobre a produção do esperma, embora exista uma publicação nacional, destinada aos profissionais, com diversas recomendações, disponível em outros centros de AMP. ${ }^{8}$ 
Encontramos nesse laboratório duas salas de coleta de esperma. Em cada uma há uma cama de $70 \mathrm{~cm}$ de largura, um carrinho com as soluções para aplicação local na parte de baixo e, na parte de cima, os vidros para coleta do esperma, esterilizados, desembalados por uma auxiliar de enfermagem para cada novo paciente. Há também uma pia com sabonete líquido e um distribuidor de papel descartável, uma lâmpada de halogênio ligada ao interruptor ao lado da porta de entrada, uma poltrona baixa e profunda (preta) e uma mesinha (também preta) com revistas eróticas ou pornográficas, do tipo que, em geral, é disponibilizado em bancas de jornal. Cada peça dispõe de uma abertura direta para o laboratório: uma janela com dupla porta de correr. $\mathrm{O}$ vidro com a amostra de esperma deve ser depositado entre as duas portas de correr.

A auxiliar do laboratório explica ao paciente que, uma vez efetuada a coleta, ele deve depositar o vidro neste espaço entre as duas portas de correr, e abrir ligeiramente a segunda porta, de maneira que as auxiliares percebam que a coleta foi completada e que o vidro está disponível para ser examinado. Este dispositivo permite, assim, que se evite ao máximo os contatos entre as pessoas em todo o processo Em conexão com estas duas salas há os “toaletes/sala de coleta”, assim como uma área reservada ao material da coleta (lençóis, depósito de roupa suja, sabonete líquido, vidros esterilizados e embalados, gaze...). Em cada ambiente para a coleta do esperma há um documento em francês, e também em árabe, na parede, contendo uma descrição da operação.

\section{Quadro 1. Condições de coleta de esperma}

\section{CONDIÇÕES DE COLETA DE ESPERMA}

\section{Urinar}

2. Lavar as mãos com sabonete

3. Enxaguar as mãos

4. Lavar a glande com sabonete

5. Enxaguar a glande com água e secar com gaze esterilizada

6. Enxaguar as mãos com a solução desinfetante e secar com gaze esterilizada.

7. Efetuar a coleta de esperma no vidro especial para a coleta

8. Fechar bem o vidro 


\section{Dimensão sexual da coleta de esperma}

Os protocolos de coleta de esperma que consultamos não abordam ou evitam, de maneira indireta, a dimensão erótica desse ato. A questão da excitação sexual necessária à produção de esperma em laboratório é frequentemente descartada, e poucas publicações tratam desse tema. Um relatório da OMS (WHO, 2002) que se refere às práticas e às controvérsias em torno da assistência médica à reprodução não menciona em nenhum momento a questão da coleta de esperma, seja do ponto de vista técnico, seja no que tange ao ponto de vista ético. No melhor dos casos, as recomendaçôes formuladas pelos Centros de Estudo e de Conservação dos Ovócitos e do Esperma, ou os centros de AMP, fazem referência à "masturbação" sem qualquer precisão, considerando provavelmente que todo mundo sabe em que consiste tal procedimento, e estipulando que "o esperma é coletado por masturbação no laboratório". A sintaxe desta frase evita precisar a identidade do sujeito gramatical dessa ação, podendo ser o paciente ou qualquer outra pessoa (sua parceira, o médico, um[a] auxiliar do laboratório, uma pessoa especializada nessa tarefa). ${ }^{9}$ Trata-se de uma imprecisão importante acerca dessas recomendações, no que concerne às condições e modalidades de produção do esperma.

O dicionário é bastante claro sobre este ponto: a masturbação é definida como uma "prática sexual solitária que consiste em toques dos órgãos genitais para provocar o prazer, o orgasmo" (Tesouro da Lingua Francesa, TLFonline). Portanto, a produção de esperma não integra, a priori, os objetivos atribuídos à prática da masturbação. O TLF lembra ainda um sentido “antigo" do termo, quando é aplicado na metáfora: "Esforço intelectual ou moral infecundo". Isto lembra as teorias médicas do século XIX, nas quais a masturbação era considerada como a causa da impotência e esterilidade (BELLIOL, 1832; GARNIER, 1887; LAQUEUR, 2003). A masturbação condensa assim na cultura ocidental as referências alheias - e talvez mesmo contraditórias - entre a procriação e a fecundidade, mesmo quando esta é assistida medicamente.

De forma corrente, a excitação daquele que deve produzir o esperma é provocada por meio da ajuda de revistas pornográficas, que podem ser trazidas pelo paciente (que pode em seguida deixá-las no laboratório ou levá-las consigo) ou compradas pelo chefe do serviço (com seu próprio dinheiro ou com verba 
do laboratório). $\mathrm{Na}$ ausência de um protocolo explícito, aparentemente não há consenso nem verba oficial para a aquisição desse material. Essa situação deixa lugar à arbitrariedade dos responsáveis do laboratório e do pessoal técnico. Eles agem segundo seus conceitos morais, seus próprios preconceitos ou suas fantasias em relação à masturbação, seu gosto ou desgosto pela pornografia, e suas noções em termos de higiene hospitalar. Quando o regulamento interno está visível na parede, no local destinado à coleta de esperma, ele se refere principalmente às condições de higiene e segurança. $\mathrm{Na}$ mesma linha de pensamento, a presença de uma parceira e sua eventual participação na coleta de esperma é uma escolha arbitrária dos serviços ou uma decisão do casal.

Além disso, a dimensão sexual da coleta de esperma está presente, na medida em que a produção de esperma em laboratório é efetuada por intermédio de práticas correntes da masturbação, como o isolamento, a manipulação do pênis, o recurso a representações mentais (pornografia) suscetíveis de facilitar a ejaculação e, eventualmente, a presença da parceira. Os relatos dos homens e das mulheres, dos pacientes e dos profissionais que os atendem se referem aos sentimentos de embaraço, segredo, de algo que deve ser escondido e que, às vezes, provoca o riso. Esses são aspectos habituais em conversas sobre sexualidade (GAIGNEBET, 1974; GIAMI et al., 1998; GUIRAUD, 1993), sendo que a masturbação guarda uma conotação específica e negativa, mesmo que esteja a serviço da procriação. Portanto, ela parece revelar um mal-estar não resolvido, uma espécie de "volta do recalcado" que toca a sexualidade em sua exclusão da prática da AMP.

A coleta de esperma é assim dotada de significados derivados de dois registros: por um lado, o registro médico, que concerne ao dispositivo em seu conjunto e à questão do tratamento bioquímico do esperma; por outro, o registro sexual, que trata da modalidade de produção de esperma e também da realização ou da renúncia da "procriação por via sexual", referente ao homem, à mulher e ao casal. A confusão entre esses registros, promovida e talvez até reforçada pelo dispositivo médico-científico no qual ela está inserida, consta dos relatos dos homens entrevistados. A experiência da coleta de esperma parece consistir num momento-chave que permite compreender a experiência do paciente. Levando em conta a dimensão cultural e de fantasia que atribui à coleta de esperma significados e conotações que ultrapassam o âmbito da prática médica e que, 
por efeito de rebote, encontram-se no próprio centro desta prática, nossa atenção se centrou nas implicaçóes e consequências subjetivas suscitadas pela coleta de esperma infértil, um aspecto não estudado em pesquisas sobre infertilidade (COEFFIN-DRIOL; GIAMI, 2004).

\section{Entrevistas}

Estudamos as representações e os significados atribuídos por homens e mulheres na situação de dever produzir esperma no laboratório. Escolhemos apresentar os principais temas das entrevistas focalizando a perturbação suscitada pela prescrição do espermograma, a incompreensão da situação associada à ausência de informações precisas, a confrontação com a prática da masturbação no meio científico, os significados atribuídos à masturbação e a posição da mulher nesse percurso. Vale dizer que o tema da coleta de esperma não havia sido objeto de uma hipótese específica antes do início das entrevistas. $\mathrm{O}$ interesse surgiu durante a investigação qualitativa. A análise se baseia no princípio de saturação, ${ }^{10}$ desenvolvido no contexto da grounded analysis (GLASER; STRAUSS, 1967) e não na frequência relativa de aparição dos enunciados e dos termos.

\section{A aversão manifestada pelos homens}

$\mathrm{Na}$ maioria dos casos, a prescrição para a coleta do esperma visando a um espermograma se inscreve num processo de tratamento médico, que já está bem avançado. Antes que a coleta de esperma seja efetuada e que os resultados sejam conhecidos, a "simples" prescrição deste exame tem valor de diagnóstico e, até, de sentença: a fertilidade masculina é posta em dúvida assim que o médico considera a necessidade de proceder à sua avaliação.

De qualquer modo, a prescrição do espermograma constitui uma (má) surpresa para o homem, sobre o qual começam a pesar suspeitas. Esses homens, por outro lado, já mal preparados social e mentalmente para se sujeitarem a exames médicos e laboratoriais, como "coletas" de "secreções", "radiografias" ou "ecografias", estão ainda menos preparados para receber instruções para se masturbarem em um laboratório. A ideia de que este exame implica um ato de conotação sexual não vem espontaneamente à mente desses homens. 


\section{Uma situação paradoxal}

O desconhecimento suscitado pela carência de informações é expressivo, pois esses homens "descobrem" progressivamente que o exame consiste na prática da masturbação. Certos homens se queixam de não terem sido avisados com antecedência do fato de que teriam que se masturbar e, portanto, mobilizar a excitação sexual necessária para colher o esperma, a priori uma questão inimaginável no contexto médico. A experiência não é vivida como "particularmente agradável":

Hector: Ah, nesta época, hein! Era assim. Eu chegava, tinha uma mulher, uma enfermeira que passava... Eu não sabia que iam fazer uma coleta. Bom, eu chego e foi justo quando íamos saindo da consulta que ele me disse: "vamos fazer um espermograma do senhor”. Ficamos com a prescrição, vamos ao laboratório... entreguei para a enfermeira. Ela me diz "sim senhor, passe para esta sala e..." "Bom, e agora?" "Mas o senhor sabe... o senhor vai... por seu esperma aqui." Foi então que compreendi que... que... que eu ia ter que me masturbar... ia ter que me masturbar... Então a gente passa no toalete... numa cabine, assim e... fiquei completamente bloqueado, passei uma hora sem poder... Porque não se pode se masturbar assim, né? Era preciso atingir um nível de excitação... e isto é... é preciso se concentrar. É preciso... esquecer que a gente está num hospital, numa cabine de toalete, que tem gente passando na frente da porta...

Albert: Bom, no início não é nada fácil, quer dizer, de se encontrar numa situação onde é preciso fazer uma coisa que não se faz todos os dias naturalmente, quer dizer, colher seu esperma. Bom, enfim, eu tinha a impressão que era uma coisa [...] Quer dizer, por um lado tem o exame médico, hein, o espermograma é um exame médico... é como uma ecografia. Enfim, um pouco mais complicado, mas assim mesmo [risos] Tem uma enfermeira lá para lhe... [risos]. Mas bom... Mas tem o lado desempenho, na verdade... A gente faz o exame, e o outro lado que é a interpretação e o tratamento, digamos, da sua ansiedade...

A prescrição médica raramente é acompanhada por comentários do médico e não parece haver uma preparação adequada para a coleta do esperma, que permanece, para esses homens, uma atividade privada e pouco compatível com o clima do laboratório. Face à confusão veiculada pelo enquadramento do laboratório, esses homens elaboram diferentes significações em resposta à situação na qual se encontram. Eles oscilam frequentemente entre duas posturas: por um lado, a adesão à ideologia e ao discurso médico e científico de banalização do ato de coleta do esperma e, por outro, o reconhecimento do caráter erótico deste ato. 


\section{A banalização por meio da adesão ao modelo médico}

Jean-Pierre interpreta a experiência de coleta do esperma no registro de sua profissão hospitalar, que lhe permite se distanciar de seu caráter pessoal e íntimo. Jean-Pierre não se "intimidou" porque o procedimento de AMP não comporta "nenhuma conotação particular, para mim é um trabalho como qualquer outro". O fato de passar exames, insiste, "me deixa frio, sem nenhuma reação particular" e, portanto, a coleta de esperma não provoca "nada em particular. Identificandose com sua profissão de biólogo, ele não se sente solidário com os homens que vivem essa experiência, e adota o ponto de vista dos profissionais que observam os pacientes perdidos nos corredores:

JeAn-Pierre: Não, aliás isto me faz rir, ver os homens que dão meia-volta na frente da porta antes de entrar, acho isto... [...]. Eles passeiam na frente da porta, não ousam entrar.

Pierre insiste em que foi fácil e rápido produzir o esperma, e o fato de que sua mulher e o pessoal técnico do laboratório se mostraram surpresos a este respeito:

PIERre: Em dez minutos, pronto, já estou de volta no corredor esperando, e todas as vezes eles ficam surpresos de ver que terminei a coleta tão rapidamente, então acho que os outros devem ter muito mais dificuldade de fazer a coleta, portanto...

A adesão ao discurso e à ideologia da técnica médica de laboratório, que se inscreve no prolongamento das primeiras reações de incompreensão da prescrição médica, parece permitir que certos homens "funcionem", em resposta e em espelho das expectativas médicas.

\section{O uso da pornografia no laboratório}

O uso da pornografia e a prática da masturbação representam práticas sexuais estigmatizadas que suscitam sentimentos de vergonha ou constrangimento, que raramente são confessados ou reivindicadas em público, sobretudo por homens casados. O imaginário sexual da pornografia não parece diretamente compatível com o da procriação. $\mathrm{O}$ álibi médico e a finalidade reprodutiva não bastam para dessexualizar a masturbação.

PIERre: Como isso se passava, a sala branca, as revistas pornográficas em cima da mesa, uma enfermeira meio constrangida que dá o pote de vidro. Portanto, eu já tinha... tinha achado graça quando ele me contou, mas, bom, eu diria que levei isto... enfim, foi tudo bem. Na realidade foi a minha mulher que ficou surpresa, mas para mim foi muito simples. 
Mouloud, que reconhece a dimensão sexual da "coleta de esperma" e a dificuldade de praticar este ato no recinto do laboratório, a partir de ordens, se mostra ainda mais constrangido de ter usado os "documentos" que ele não se atreve a chamar de "pornográficos". O "ato de prazer" aparece assim ainda mais incompatível com o enquadramento do laboratório e a finalidade da "coleta":

Mouloud: Às vezes eu pedia meio dia de folga para fazer a coleta... era um pouco... era um pouco difícil para a masturbação também. Mas se nos dão documentos, umas... para ver, assim, livros para estimular, mas... Sim, a cabeça meio... Para mim, o fato de vir, assim, de vez em quando ao hospital para fazer coletas, assim, isto me incomoda um pouco, sabe? Não é... não fico à vontade. Não venho com prazer. Sou obrigado a vir, assim isto já é... Ainda por cima, vir assim, com hora marcada, e é durante este tempo, uma meia hora, que tem que se ter prazer. E mesmo é meio difícil.

Para este homem, a prática da coleta de esperma não está completamente despida de seus significados eróticos e a dificuldade de transformar a masturbação totalmente em um ato médico contribui ao constrangimento. Esta prática continua sendo uma maneira de "ter prazer" sob comando, num contexto não apropriado.

\section{Quando o sexo não encontra seu lugar: a intimidade sexual ameaçada}

Esses homens devem se masturbar "sob comando", e tanto mais que se trata de um contexto não apropriado, no qual eles têm a impressão de não dispor da intimidade necessária. Alguns desenvolvem a fantasia de estar se masturbando em público ou pelo menos que todos - enfermeiras e outros pacientes na sala de espera - sabem o que eles estão fazendo lá.

Hector vivenciou mal o fato de ter que se masturbar numa cabine e constatar que era difícil conseguir ejacular. $\mathrm{O}$ constrangimento associado a esta situação parece ampliado pela atitude da enfermeira:

Hector: Eu cheguei. Era inverno. E a senhora me disse "Bom, o senhor vai esp... esperar um pouquinho aqui porque tem um senhor... na cabine". Dez minutos mais tarde, a porta se abre e o senhor sai. "O senhor está pronto?", ela pergunta. "Não, não consegui”. O senhor que estava saindo não tinha conseguido se masturbar. E isto também me aconteceu... uma vez. Mas depois me acostumei... não tenho mais problema.

Esses homens se sentem incapazes de medicalizar a prática da masturbação nas modalidades impostas pela instituição, e podem ter dificuldade de produzir o esperma necessário, o que se torna mais um motivo de constrangimento e humilhação. Para muitos, a masturbação é um ato erótico que não se enquadra 
nesse contexto. Acrescente-se ainda um sentimento de impotência: "não consegui". A instituição não consegue medicalizar completamente esta prática: por um lado, a conotação erótica é necessária - pornografia, orgasmo - e, por outro, as circunstâncias são organizadas de forma desajeitada, aumentando o constrangimento e dificultando sua realização.

\section{A confirmação das mulheres: a amplificação do nojo}

Este é o depoimento das mulheres que não participaram diretamente da produção de esperma. Elas relataram suas reaçôes face ao que perceberam da situação, a maneira como reagiram, diante do que foi contado e comentado pelos cônjuges. Essas mulheres expressaram reações desagradáveis muito mais intensas do que as dos homens: “sórdido" é o termo empregado frequentemente.

Para as mulheres, o nojo pode efetivamente corresponder ao fato de que a prática da masturbação é inaceitável, ainda que seja por uma "boa” razão.

Mireille: Ah não, eu não fui com ele... Não, não. Mas ele não me propôs, mas acho que se ele tivesse proposto, eu não... não. Não faz parte dos meus [risos] dos meus hábitos, enfim, não sei. Enfim, se ele tivesse me proposto de ir com ele, etc., não. Sei lá, isto não me agrada...

ENTREVISTADOR: é pelo fato de que ele tenha que se masturbar que você...?

M: Sim, isto me incomoda. Sim, enfim, tenho horror disto. Mesmo se é por uma "boa" razão. Não, ele não se importaria, ainda que eu pense que, na verdade, ele aceitaria se eu propusesse ir com ele. Aparentemente ele se vira muito bem sozinho. [risos].

Como para os homens, é a contiguidade entre o erótico e a medicalização, duas entidades aparentemente dificilmente conciliáveis, e o caráter não apropriado do lugar em que deve se concretizar este ato, que tende a provocar a rejeição:

FRANCINE: Bom, da primeira vez ele suportou isto como uma obrigação. Eu estava com ele, mas fiquei na sala de espera. Eles propuseram que eu fosse chamada, mas ele não quis. Eu não sabia, só fiquei sabendo quando ele saiu... mas para mim é inconcebível que eu esteja presente... não pensei que iam me propor assistir. Sinceramente, não pensei. Imaginava isto num lugar com revistas, sei lá, mas certamente que a esposa não estaria lá. Então eu o acompanhei ao laboratório, ele entrou e efetivamente havia um cômodo e a enfermeira perguntou se ele queria que eu fosse ajudá-lo. Ele respondeu "não, me viro sozinho". Ele só me disse isto quando tinha terminado. Quer dizer, se isto pode ajudá-lo, e se isto pode evitar que seja uma obrigação, que seja um suplício, faço tudo o que for preciso. Mas também não quero atrapalhar. Meu marido é muito tímido, hein! Talvez seja por isso que ele não quis que eu fosse quando propuseram. Não deve ser assim. E na realidade, sim! [risos]. Acho que ele não ousou dizer 
sim. Talvez ele tenha pensado "se digo que sim, eles vão pensar, enfim, a enfermeira vai pensar que isto vai virar um motel", quando na verdade para ele isto é um exame médico. Ainda assim isto é terrível.

Nesse sentido, tudo o que tende a lembrar o contexto médico - e, particularmente, o exame médico com suas conotações sexuais - é fonte de constrangimento para as mulheres, ainda que elas estejam habituadas ao exame médico genital (no ginecologista) e que a demanda de assistência médica à procriação venha principalmente delas. Mas elas parecem conceber a proximidade entre esses dois registros como particularmente insuportável, ou para a representação que se fazem da sua sexualidade:

LOUISE: Não quero que isto acabe se tornando sórdido. Não quero vê-lo pondo esperma num... [risos] num vidrinho, isto não é muito atraente. [risos] Da mesma maneira que, quando vou ao ginecologista, não gostaria que ele ficasse do lado do ginecologista enquanto... enquanto ele me examina. Portanto... portanto isto é para que cada um tenha ainda um pouco de... de intimidade, talvez, de reserva em relação a isso. Eu não tinha vontade e também acho que ele não teria necessariamente gostado que eu estivesse lá. Eu podia... é verdade que podia, mas... mas visto, não sei, o lugar, as paredes descascando, meio sórdido [risos].

Annie descreve uma experiência vivida por seu cônjuge como uma "obrigação" e, até, como um "suplício" ao qual ela não quis se associar. Percebe-se bem, ao ler seu depoimento, que ela não quer se associar ao que é descrito como uma forma de sexualidade desviada, em face da qual ela se sente estranha, e não deseja testemunhar uma cena que lembra um cenário sexual que ela rejeita fundamentalmente:

ANNIE: A primeira vez tudo se passou muito mal. Chegamos num laboratório... sendo... "Pode entrar, façam aqui". Eles nunca devem fazer. Portanto, era muito sórdido porque lhe disseram para fazer a coleta num banheiro de um metro quadrado. E então, ele comentou... nós comentamos com o ginecologista que depois nos mandou... num outro laboratório em Paris, na verdade. Sim, eles estão acostumados. E efetivamente foi muito diferente, era mais sociável... se isto pode se chamar de sociável. Em todo caso, não num banheiro de um metro quadrado. Enfim, neste lugar as pessoas são mais habituadas, você não tem que desfilar pelo laboratório com um vidrinho na mão para entregar na recepção ou... tem um mínimo de... E bom, todos os homens que estavam lá, estavam esperando para... fazer isto também.

O testemunho feminino confirma, portanto, o masculino, amplificando-o em parte por empatia: este esperma provoca constrangimento e nojo, também pela esterilidade que revela e pelo modo de coleta - paradoxal, parassexual - do qual faz objeto. 
Françoise, como a maioria das mulheres entrevistadas, preferiu não acompanhar seu cônjuge para este exame, e descreve o que sentiu quando ouviu o que ele contou de sua experiência:

ENTREVISTADOR: Não lhe propuseram acompanhá-lo?

FRANÇOISE: Não, e confesso que nunca pensei nisto. Não, porque, além disso, já que estamos falando nisso, ele descreve de maneira quase sórdida, portanto... não me dá vontade de... de ir. Não, mas... enfim, é sórdido este aspecto de, fechado num quartinho, as revistas...

\section{Conclusão}

A pesquisa aqui apresentada permitiu desvendar um aspecto das tecnologias biomédicas que revela o preço emocional despendido pelas pessoas ao se engajarem na realização desse projeto. Sentimentos de incompreensão, constrangimento, vergonha, humilhação, coação e de nojo foram expressos pelos homens, em torno do fato de deverem se masturbar em um quartinho cheio de revistas pornográficas para produzir esperma. Sentimentos de repugnância e de desgosto foram referidos por algumas mulheres, ao evocarem essas cenas, que nem elas nem seus cônjuges desejaram que elas assistissem. A expressão de sentimentos tão desagradáveis revela a face oculta da esperança suscitada pelo sucesso técnico da AMP, sucesso que relega a segundo plano toda a aflição e os sofrimentos que surgem quando o recurso a essas técnicas não é possível, ou que sua aplicação conduziu ao fracasso. No entanto, entre o sucesso e o fracasso das técnicas de AMP, se desenrola o percurso dos exames e dos testes suportados pelas mulheres em primeiro lugar, sobre as quais pesa sempre, em primeira intenção, a suspeita de infertilidade. Mas quando os médicos voltam seu olhar para os homens e sugerem que é preciso verificar a infertilidade do lado masculino, um colapso ameaça: a simples hipótese de esterilidade masculina evoca imediatamente um diagnóstico sem apelo, que será confirmado para muitos deles. É então que o valor simbólico do esperma se transforma radicalmente, e que sua produção em condições não apropriadas vai suscitar a repugnância desses homens e mulheres.

No passado inaceitável pela crença das religiões monoteístas, a coleta de esperma por meio da masturbação para a AMP se tornou uma prática biomédica banal e o emblema desse dispositivo científico. Ora, nossas observações e 
entrevistas evidenciaram que a banalização médica e a técnica da coleta de esperma e sua construção simbólica como simples prática biomédica está longe de ser inteiramente realizada. A experiência dos homens que contribuíram para nossa investigação, assim como das mulheres que os acompanharam nesse percurso, indica as dificuldades que enfrentaram diante dessa situação complexa, assim como as estratégias empregadas para enfrentá-la. O constrangimento dos diferentes atores implicados nessa situação (médicos, enfermeiras, usuários) demonstra que a erotização da prática da masturbação continua presente e produz seus efeitos emocionais sobre todos os protagonistas. O nojo experimentado nessa situação marca, assim, os limites da banalização da medicalização dos líquidos corporais.

A medicalização da coleta de esperma, que deveria permitir que a biomedicina abolisse o erotismo da atividade sexual e da masturbação, com o objetivo de realizar uma procriação por via não sexual, não foi alcançada. Os homens que entrevistamos se sentiram desestabilizados pela confusão entre o caráter médico da prática de coleta do esperma e a dimensão erótica da masturbação, sem a qual a coleta de esperma não pode ser realizada. A instituição bem o sabe, pois coloca material pornográfico à disposição desses homens. É ao preço desta transformação do erótico em médico que a coleta de esperma parece finalmente ser possível.

Por fim, este trabalho confirma as observações já realizadas por Inhorn (2007), segundo as quais os pesquisadores ainda não ouviram suficientemente os homens em situações nas quais seus corpos e suas subjetividades são manipulados por tecnologias da biomedicina, tanto quanto o são os corpos das mulheres. Conhecemos ainda muito pouco acerca das experiências dos homens no campo da saúde sexual, dos direitos sexuais e dos direitos reprodutivos, e este estudo convoca ao desenvolvimento das pesquisas neste campo sobre os homens. ${ }^{11}$

\section{Referências}

AUGÉ, M. L'anthropologie de la maladie, L'Homme, v.26, n. 1-2, p.81-90, 1986.

BELLIOL, J.-A. De l'impuissance ou perte de virilité. Paris: s/ed, 1832.

BIALE, D. Eros juif. Arles: Actes Sud, 1997.

ClARKE, A. Disciplining Reproduction. Modernity, American Life Sciences, and the Problems of Sex, Berkeley: University of California Press, 1998.

COEFFIN-DRIOL, C.; GIAMI, A. L'impact de l'infertilité et de ses traitements sur la vie sexuelle et la relation de couple : revue de la littérature. Gynécologie, Obstétrique, Fertilité, v. 32, n. 7-8, p. 624-637, 2004. 
DOUGLAS, M. De la souillure: essai sur les notions de pollution et de tabou. Paris: Maspero, 1971.

FOUCAULT, M. Histoire de la sexualité, tome 1: La volonté de savoir. Paris: Gallimard, 1976.

GAIGNEBET, C. Le folklore obscène des enfants. Paris: Maisonneuve et Larose, 1974.

GARNIER, P. Onanisme seul et à deux sous toutes ses formes et leurs conséquences. Paris: Garnier, 1887.

GEERTZ, C. Local Knowledge. Further essays in interpretive anthropology. New York: Basic Books, 1983.

GERRIS, J. Methods of semen collection not based on masturbation or surgical sperm retrieval, Human Reproduction Update, v. 5, n. 3, p. 211-215, 1999.

GIAMI, A.; VEIL, C.; GROUPE RITS. Des infirmières face au sida. Représentations et conduites, permanence et changements. Paris: Editions de l'Inserm, 1994.

GIAMI, A. et al. Un exemple d'articulation de méthodes d'analyse qualitatives et quantitatives sur des entretiens semi-directifs : les représentations du handicap. Bulletin de Méthodologie sociologique, v. 47, p. 49-77, 1995.

GIAMI, A.; OLOMUCKI, H.; DE POPLAVSKY, J. Enquêter sur la sexualité et le sida : les enquêteurs de l'ACSF. In: BAJOS, N. et al. (org.). La sexualité aux temps du sida. Paris: PUF, 1998. p. 66-116.

GLASER, B.; STRAUSS, A. The Discovery of Grounded Theory. Chicago: Aldine, 1967.

GODELIER, M. Métamorphoses de la parenté. Paris: Fayard, 2005.

GUIRAUD, P. Dictionnaire érotique précédé d'une introduction sur les structures étymologiques du vocabulaire érotique. Paris: Payot, 1993.

HERDT, G. Guardians of the Flutes. Chicago: Chicago University Press, 1981.

HÉRITIER, F. Stérilité, aridité, sécheresse : quelques invariants de la pensée symbolique. In: AUGE, M.; HERZLICH, C. (org.). Le sens du mal. Anthropologie, histoire, sociologie de la maladie. Paris: Editions des Archives Contemporaines, 1984. p. 123-154.

HÉRITIER-AUGÉ, F. Le sperme et le sang. De quelques théories anciennes sur leur genèse et leurs rapports. Nouvelle Revue de Psychanalyse, v. 32, p. 111-122, 1985.

HIRT, J.-M. Le cinéma de la mise à nu. Nouvelle Revue de Psychanalyse, v. 29, p. 249268, 1984.

INHORN, M. Masturbation, semen collection and men's IVF experiences: anxieties in the Muslim world. Body \& Society, v. 13, n. 3, p. 37-53, 2007.

JOUANNET, P.; DAVID, G. Practical and psychological aspects of sperm collection. Journal of Gynecology Obstetrics \& Biology Reproduction, v. 6, n. 1, p. 55-64, 1977.

KIRKMAN, M. Saviours and satyrs: ambivalence in narrative meanings of sperm provision. Culture, Health \& Sexuality, v. 6, n. 4, p. 319-335, 2004. 
KLEINMAN, A. The illness narratives: suffering, healing and the human condition. New York: Basic Books, 1988.

LAPLANTINE, F. Anthropologie de la maladie. Paris: Payot, 1986.

LAQUEUR, T. Solitary sex : a cultural history of masturbation ? New York: Zone Books, 2003.

MOORE, L. J., Extracting men from semen: masculinity in scientific representations of sperm. Social Text, v. 20, n. 4, p. 91-119, 2002.

MURraY, M. (Ed.). Critical Health Psychology. London: Palgrave Mac Millan, 2004.

SONTAG, S. Le sida et ses métaphores. Paris : Christian Bourgois, 1988.

STOLLER, R. Porn myths for the twentieth century. New Haven: Yale University Press, 1991. SZASZ, T. Fabriquer la folie. Paris: Payot, 1976.

WORLD HEALTH ORGANIZATION. Current practices and controversies in assisted reproduction. Report of a WHO meeting. Department of Reproductive Health and Research, Family and Community Health. Geneva, WHO, 2002.

\section{Notas}

1 "Sécu" é a expressão usada coloquialmente para designar o sistema de saúde francês: Sécurité Sociale (equivalente ao SUS).

${ }^{2}$ Os nomes dos participantes foram modificados para proteger seu anonimato.

${ }^{3}$ Esta pesquisa foi financiada pelo Institut National de Santé et Recherche Médicale (INSERM), Paris, França, e não apresenta nenhum conflito de interesses. A pesquisa foi realizada segundo as normas internacionais referentes à ética da pesquisa com seres humanos e as leis francesas, com a aprovação e sob a supervisão do INSERM.

${ }^{4}$ Este material de observação está em processo de análise e será objeto de publicação posterior.

${ }^{5}$ Após a lei de 20 dezembro 1988 na França, relativa à proteção das pessoas que se prestam a pesquisas biomédicas (dita lei Huriet), os investigadores científicos são obrigados a obter o consentimento daqueles que participam da pesquisa. Este consentimento deve ser "livre, esclarecido e expresso": 1) livre porque a pessoa deve ter a possibilidade de se recusar a participar da pesquisa sem que isso acarrete quaisquer consequências ; (2) esclarecido, pois a pessoa deve receber informação acessível e detalhada sobre a pesquisa, sobretudo acerca de seus objetivos e riscos potenciais; (3) expresso significa que não há dúvidas em torno do consentimento.

${ }^{6}$ Termo oficialmente escolhido, que consta do Guia de boas práticas clínicas e biológicas em assistência médica à procriação, redigido pela Comissão Nacional de Medicina e Biologia da Reprodução e do Diagnóstico Prénatal publicado no Jornal Oficial da França, em 28 de fevereiro de 1999.

${ }^{7}$ Em um trabalho de antropologia realizado na Califórnia em bancos de esperma, Diane Tolber descreveu com detalhes a produção de esperma (TOLBER, 2001). 
${ }^{8} \mathrm{O}$ Guia de boas práticas clínicas e biológicas para a assistência médica à procriação, redigido pela Comissão Nacional de Medicina e Biologia da Reprodução e do Diagnóstico Pré-natal (CNMBRDP) não menciona o termo "masturbação" nem a técnica a ser utilizada para a "coleta de esperma". Esse mesmo documento faz referência às técnicas, visando que a esterilidade dos materiais seja assegurada, nos locais designados para a transferência dos gametas.

${ }^{9}$ No início da década de 60, os terapeutas sexuais William Masters e Virginia Johnson por vezes recorriam a "substitutos de parceiros" (surrogate partners), para realizar o tratamento de perturbaçôes sexuais de homens que consultavam individualmente. Posteriormente esta prática foi abandonada.

${ }^{10} \mathrm{O}$ princípio de saturação elaborado na grounded theory repousa sobre a ideia de que se coleta o material, que vai sendo analisado ao mesmo tempo, na medida em que se propõem nas entrevistas seguintes as ideias e as hipóteses que emergiram nas primeiras análises. O término da coleta de novas entrevistas se dá a partir do momento em que não se encontra nada de novo nos relatos, supondo-se assim que a questão está esgotada.

${ }^{11}$ A. Giami e D. Vasconcellos-Bernstein elaboraram o projeto e os instrumentos de pesquisa. A. Giami participou da observação de consultas médicas, coleta de dados através da entrevista individual dos pacientes, discussão do material coletado, e elaboração do artigo. 
Infertile sperm collection in hospital laboratories: sexual or medical practice? The protocols of medical assistance to procreation involve a biological examination of sperm, conducted through masturbation practiced in inappropriate places for a practice generally considered erotic. We conducted ethnographic research in two major Parisian hospitals. The men and women who participated expressed subjective reactions, involving embarrassment, shame, disgust and disgust on the practice of masturbation in this context. The confusion between the medical and sexual records, difficulty in de-sexualize a practice that remains taboo, and the sterile nature of sperm produced in such circumstances would be the cause of emotional reactions experienced in relation to sperm when it is produced in the medical context.

> Key words: sperm collection; infertility; masturbation; assisted reproductive technologies. 